\title{
As cartas de Saussure: um lugar singular em sua produção
}

DOl: http://dx.doi.org/10.21165/el.v49i3.2528

\author{
Marcen de Oliveira Souza' \\ Eliane Silveira ${ }^{2}$
}

\section{Resumo}

Durante seu percurso acadêmico, Ferdinand de Saussure escreveu cartas a pesquisadores e eruditos do século XIX. A maioria delas chegou ao seu destino, enquanto outras não foram enviadas. Apesar de veicularem assuntos pessoais, são fontes importantes de pesquisa para a compreensão do percurso teórico do genebrino nos estudos linguísticos. Neste artigo, propomos examinar cinco cartas: três enviadas, que versavam sobre os anagramas, endereçadas, respectivamente, ao colega Antoine Meillet e ao poeta Giovani Pascoli; e outras duas, não enviadas, com temáticas sobre a passagem do genebrino em Leipzig e sobre o linguista americano W. D. Whitney. A partir destas considerações, nossa questão é: o que essas cartas/interlocuções nos ensinam sobre o percurso de pesquisador de Saussure? Isso posto, entendemos que a presente investigação possibilitará uma compreensão maior do pensamento saussuriano, em seu movimento de fundação da linguística moderna.

Palavras-chave: Ferdinand de Saussure; cartas; anagramas; cartas não enviadas.

\footnotetext{
1 Universidade Federal de Uberlândia (UFU), Uberlândia, Minas Gerais, Brasil; marcensouza@hotmail.com; https://orcid.org/0000-0002-9521-6319

2 Universidade Federal de Uberlândia (UFU), Uberlândia, Minas Gerais, Brasil; eliane.m.silveira@gmail.com; https://orcid.org/0000-0002-4862-4547
} 


\section{Les lettres de Saussure: une place singulier dans sa production}

\section{Résumé}

Au cours de sa carrière universitaire, Ferdinand de Saussure a écrit des lettres à des chercheurs et universitaires du XIXe siècle. La plupart dientre eux ont atteint leur destination, tandis que drautres n>ont pas été envoyés. Bien quils véhiculent des questions personnelles, ils sont dimportantes sources de recherche pour comprendre le chemin théorique du Genebrino dans les études linguistiques. Dans cet article, nous proposons diexaminer cinq lettres: trois envoyées, traitant d'anagrammes, adressées respectivement au collègue Antoine Meillet et au poète Giovani Pascoli; et deux autres, non envoyés, avec des thèmes sur le passage du Genevois à Leipzig et sur le linguiste américain W. D. Whitney. A partir de ces considérations, notre question est: que nous apprennent ces lettres / interlocutions sur la carrière de chercheur de Saussure? Cela dit, nous comprenons que la présente enquête permettra une meilleure compréhension de la pensée saussurienne, dans son mouvement pour fonder la linguistique moderne.

Mots-clés: Ferdinand deSaussure; lettres; anagrammes; lettres non envoyées.

\section{Ferdinand de Saussure: entre manuscritos e cartas}

Dentre as diversas maneiras de se homenagear o linguista Ferdinand de Saussure, de Ihe fazer determinada apresentação, seja sobre algum aspecto pessoal ou acadêmico, é comum lembrarmos de fatos que marcaram sua trajetória. Além de lhe outorgar, regularmente o título de fundador da Linguística Moderna ${ }^{3}$, relembramos, em alguns momentos, quando o genebrino faz menção à sua epistelofobia ${ }^{4}$, mencionada em uma carta à Meillet, em 1894, ou quando alude sobre seu longo silenciamento, situação enfatizada agora em uma carta à Louis Havet, em 1910, por não haver sequer publicado outro livro, além do Mémoire.

Observa-se, no entanto, uma tensão entre o reconhecimento que a posteridade lhe outorga, postumamente, como fundador da Linguística Moderna, e os adjetivos que ele mesmo se atribui, em seus medos e silêncios. Tal tensão é maximizada se considerarmos que

\footnotetext{
3 É possível considerá-lo como fundador da Linguística Moderna a partir do momento em que Saussure institui o ponto de vista sincrônico nos estudos sobre as línguas e a linguagem, assim como pelo fato de haver delimitado a língua como sistema de signos linguísticos. Nesse sentido, rompe-se com os impasses do empirismo da perspectiva histórico-comparatista, conforme pontua Normand (2009).

4 Nesta carta, Saussure menciona este termo pontuando a dificuldade que ele tinha em escrever, principalmente nas cartas, sobre determinados assuntos de caráter teórico, no campo dos estudos linguísticos.
} 
a paternidade da linguística moderna se funda a partir da publicação da obra conhecida como Curso de Linguística Geral (1916), doravante CLG ou Cours, editada e publicada após seu falecimento, com base nas anotações dos alunos que assistiram os cursos ministrados na Universidade de Genebra ${ }^{5}$. Todavia, se essa tensão ainda persiste, não é injustificável, pelo muito que Saussure escreveu, não temendo a pena, e neste caso, silenciando-se menos ainda, conforme atestam a quantidade de manuscritos ${ }^{6}$.

$\mathrm{Na}$ esteira desse reconhecimento, as cartas redigidas por Saussure ao longo desse percurso (de "silêncio" e de "aversão à letra") atestam, ao contrário dessas características, um linguista perscrutador, inquiridor, que não se deixava abater pelos obstáculos encontrados em cada pesquisa empreendida. Tal posicionamento nos é testemunhado pelas inúmeras correspondências remetidas ao longo de sua vida. Fehr (2000), no levantamento bibliográfico da produção manuscrita de Saussure, contabiliza mais de uma centena desses documentos, considerando apenas as cartas de caráter acadêmico ${ }^{7}$.

As cartas acadêmicas começam a ser publicadas a partir dos anos de 1960. Parecenos que o interesse por essas correspondências está relacionado à publicação do inventário de manuscritos saussurianos por Robert Godel em 1960 no Cahiers Ferdinand de Saussure. 17. O arquivo de origem desse inventário é denominado Brouillons de lettres de F. de Saussure encontra-se na Biblioteca de Genebra catalogado como Ms. Fr. 3957. A partir de então, linguistas como Émile Benveniste, Roman Jakobson, Jean Starobinski, Anouar Louca, Giuseppe Nava, Aldo Prosdocimi e Ana Marinetti, M. Décimo, Pierre-Yves Testenoire, dentre outros, publicaram e analisaram as cartas saussurianas.

Com base nessas publicações, é possível se inteirar dos diversos interlocutores do mestre genebrino, dentre os quais, citamos: Karl Brugmann, reconhecido professor alemão, precursor do movimento neogramático; J. Baudouin de Courtenay, linguista russo, iniciador dos estudos fonológicos; Antoine Meillet, antigo aluno de Saussure e

5 Para uma melhor compreensão do processo editorial do Curso de Linguística Geral (1916), ver Prefácio à primeira edição, publicado pelos editores no próprio CLG.

6 Hoje disponíveis as Universidades de Genebra e de Harvard, principalmente, totalizando quase trinta mil folhas.

7 As cartas existentes não são, de fato, somente do domínio universitário. É possível observar a existência de cartas pessoais, vindas a público no final do século $X X$, a partir das publicações de Quijano (2008). Essas missivas, ao contrário das acadêmicas, situam-se, em grande parte, na adolescência saussuriana e são perpassadas por um tom suave e despreocupado, característico de alguém que ainda não entrou na vida adulta. De um modo geral, são cartas escritas durante suas férias, em viagens realizadas fora da Suíça, em que o jovem genebrino relatava suas aventuras, principalmente à mãe, quando estava aos pés dos montes suíços. Outras cartas mostram o aluno universitário em Leipzig, a partir de 1876, e expõem seu lado afetuoso e saudosista, ao remeter alguma carta a Henri de Saussure, seu pai. 
professor da École de Hautes Études; William D. Whitney, renomado linguista americano, autor do livro A vida da linguagem; Max Van Berchem, orientalista e precursor dos estudos da epigrafia árabe; Giovani Pascoli, poeta e professor italiano, dentre vários outros.

A quantidade considerável de correspondências é uma pista de que elas agregam informações diversas, e principalmente sobre aspectos teóricos às vezes ausentes nos próprios manuscritos dedicados ao tema tratado nas cartas. De fato, essas cartas são reconhecidas como pontos estratégicos pelos estudiosos da fortuna teórica de Saussure, pois possibilitam a compreensão do percurso do linguista em suas pesquisas sobre os fatos de língua e de linguagem.

Neste trabalho, não trataremos aqui de abordar as cartas com base em uma perspectiva metodológica específica sobre tipo de gênero textual. Nosso objetivo ébem mais modesto, isto é, o de examinar, pela leitura das correspondências selecionadas, aspectos do movimento teórico-acadêmico saussuriano ali entrevistos. Para isto, propomos abordar cinco cartas escritas por Ferdinand de Saussure, sendo três cartas enviadas e duas retidas. As três primeiras centram-se na pesquisa sobre os anagramas: uma enviada a Antoine Meillet, em 12 de novembro de 1906 e as outras duas remetidas ao poeta Giovani Pascoli, datadas, respectivamente, de 19 de março e de 06 de abril de 1909.

As outras duas, abordadas a partir do tópico "cartas não enviadas", visam analisar dois documentos de Saussure que, sendo redigidos a possíveis interlocutores, não foram enviados por motivos diversos. O tema dessas duas cartas é exclusivamente teórico e está diretamente ligado à posição de Saussure como linguista, e sua relação com os linguistas contemporâneos. De um modo geral, a primeira expõe alguns fatos acadêmicos vivenciados quando o jovem genebrino estudava na Universidade de Leipzig e a segunda versa sobre o colega americano, Whitney.

\section{A primeira carta de Saussure a Meillet sobre os Anagramas}

Antoine Meillet foi um dos principais interlocutores de Saussure, desde o momento em que se conheceram na Universidade de Paris, na École des Hautes Études, na década de 1880. A maioria das correspondências trocadas entre eles foi publicada no CFS n. 21, em 1964, sob a orientação do renomado linguista francês Émile Benveniste. Mais precisamente, temos dezenove cartas publicadas por Benveniste, uma por Jakobson e duas recentemente publicadas por Testenoire (2015), que abrangem o período de 1884 a 1912.

A maior parte das cartas foi disponibilizada em conjunto, cedidas por familiares dos destinatários; outras, em menor número, foram encontradas ao acaso, escondidas em algum livro ou guardadas em arquivos pessoais. É o caso da carta publicada por Roman 
Jakobson, em 1971, a qual foi descoberta ao acaso dentro de um livro da biblioteca de Saussure, e que the foi cedida pela viúva do linguista. Essa carta, endereçada à Meillet ${ }^{8}$, é intitulada como "A primeira carta de Saussure sobre os anagramas" (JAKOBSON, 1990, p. 17). Além disso, destaca-se que o conteúdo de algumas cartas testemunha a ausência de outras, conforme pontua Benveniste (1964, p. 21), quando expressa que "Algumas parecem faltar [...] uma provavelmente (anterior à de 23 de setembro de 1907), onde ele Ihe faz a primeira menção de suas pesquisas sobre o saturnino." 9 .

No que tange à produção saussuriana sobre os anagramas, convém ressaltar dois aspectos: i) a quantidade de material e ii) a quantidade de cartas. Sobre o primeiro, Saussure começou a pesquisa sobre os anagramas no início de 1906, manuscrevendo um total de quase cento e vinte cadernos sobre o tema ${ }^{10}$. Quanto ao segundo aspecto, observa-se que, durante os quase três anos de pesquisas sobre os anagramas (19061909), o linguista escreveu em torno de trinta cartas, das quais seis foram endereçadas ao colega parisiense Antoine Meillet ${ }^{11}$. Neste tópico, deter-nos-emos somente na primeira dessas cartas, que foi redigida em 12 de novembro de 1906. Ela é iniciada com um agradecimento de Saussure a Meillet por ter Ihe homenageado em uma aula inaugural em Paris, e também pelo convite para participar de uma Conferência no Collège de France. Após essa passagem, o mestre genebrino diz:

Creio que minha última carta era de Roma. Não sei se por inspiração dos túmulos dos Cipiões ou por outro motivo, passei, em seguida, meu tempo a [tratar] escavar o verso saturnino, sobre o qual chego a conclusões diferentes das de Louis Havet. Mas vou imediatamente acrescentar a isso um pedido que tencionava fazerIhe, e a propósito do qual o senhor terá recebido uma carta se não tivesse me prevenido [,] a respeito de outra coisa: Poderia o senhor, por amizade, fazer-me o favor de ler as notas sobre os Anagramas nos poemas homéricos que reuni entre outros estudos, no decorrer das pesquisas sobre o verso saturnino, e a respeito dos quais eu o consulto [-aria, se o senhor] confidencialmente, porque é quase impossível àquele [que ele] que teve a ideia saber se é vítima de uma ilusão, ou

8 Vale ressaltar que o primeiro anúncio em carta sobre os anagramas ocorreu em julho de 1906, em uma longa carta destinada a Charles Bally publicada parcialmente por Jean Starobinski (1970), e por Prosdocimi e Marinetti (1990), nos CFS n. 44.

9 Tradução nossa de: "Quelques-unes semblent manquer [...] une autre probablement (antérieure à celle du 23 septembre 1907), où il lui faisait la première annonce de ses recherches sur le saturnien"..

10 A hipótese anagramática fundamentou-se no fato de que diversas obras literárias da antiguidade clássica, e mesmo de períodos posteriores, eram escritas a partir da fragmentação de nomes próprios (cf. STAROBINSKI, 1971).

11 Além de Charles Bally e de Antoine Meillet, Saussure escreveu algumas cartas sobre os anagramas a Léopold Gautier, ao diretor do Colégio de Eton e ao poeta italiano Giovani Pascoli. 
se alguma coisa de verdadeiro está na base de sua ideia, ou se a verdade existe apenas parcialmente. Procurando por toda a parte alguém que pudesse ser o controlador de minha hipótese, há muito que vejo apenas o senhor; [mas] e como eu Ihe pediria ao mesmo tempo para manter toda discrição com relação a essa hipótese, talvez ilusória, é ainda ao senhor que eu recorreria por ter toda confiança nesse aspecto. Não escondo que, se aceitar, a próxima correspondência lhe levará doze ou quinze cadernos de notas. Entretanto, tais notas foram redigidas tendo em vista um leitor, lei que me impus, a fim de ter, por assim dizer, um primeiro controle [...]. (SAUSSURE apud JAKOBSON, 1990, p. 4).

Esse trecho nos traz importantes informações a respeito dos estudos anagramáticos: i) um panorama de seu início; ii) o corpus de análise; iii) a confidencialidade do assunto; iv) a possível ilusão da hipótese; v) a quantidade de cadernos até então manuscritos e vi) a escrita tendo em vista um leitor. Sobre o primeiro ponto, sabe-se que a carta à qual Saussure se refere foi escrita em 23 de janeiro de 1906. Ao contemplar as inscrições latinas em uma visita aos antigos monumentos em Roma, Saussure inicia a análise dos versos saturninos no primeiro semestre de 1906.

Após escrever cerca de 17 cadernos sobre a poesia saturnina, o corpus de análise investigado por Saussure passa a ser os textos de Homero, a llíada e a Odisseia, confirmando, nos textos gregos, a presença de anagramas. Em uma carta à Bally, em julho de 1906, a hipótese sobre os anagramas é elaborada como sendo a fragmentação fônica de nomes próprios (de pessoas, de lugares, etc.) e a utilização desses fragmentos para a composição dos versos poéticos.

De meados de julho até o final de 1906, as pesquisas anagramáticas avançam, totalizando uma produção de quinze cadernos sobre os anagramas homéricos ${ }^{12}$. Como nos revelam algumas passagens dessa primeira carta à Meillet, o assunto dos anagramas era tratado a sete chaves. Tal fato permite-nos questionar: porque Saussure pediria tal discrição/ confidencialidade sobre suas investigações no campo da literatura? Seria a hipótese anagramática da ordem do absurdo, ou haveria certa precaução para não revelar a descoberta de um antigo segredo, antes que tivesse total certeza?

Segundo Testenoire (2013), a hipótese sobre os anagramas traz, diferente de outras reflexões saussurianas sobre fatos de linguagem, um grau maior de ineditismo. Embora haja pontos convergentes entre os trabalhos de Saussure no campo da linguística e aspectos da produção sobre os anagramas ${ }^{13}$, essa hipótese não faz laço com outros pesquisadores, justamente pela novidade que agrega (TESTENOIRE, 2013). É neste ponto que podemos afirmar a necessidade de se estabelecer uma interlocução sobre este tema,

12 Sabe-se que, no total, Saussure escreveu 24 cadernos dedicados aos textos homéricos.

13 Conforme Silveira (2007), Silva (2009), Testenoire (2013) e Souza (2017). 
via cartas, com pesquisadores que estivessem ligados à Saussure, principalmente por vínculos de amizade.

No entanto, há momentos em que Saussure é cercado pela incerteza da veracidade do anagrama, questionando-se se não estava sendo vítima de uma ilusão, levando-o a buscar um controlador externo, neste caso, Antoine Meillet. É fato, todavia, que Charles Bally fora o primeiro controlador; não se sabe, ao certo, a razão por Saussure buscar apoio em outro colega. Em consonância com a necessidade de um controle externo, o genebrino menciona a lei de escrever essas análises tendo em vista um leitor. Tal aspecto é interessante na medida em que se pode observar um grau de refinamento na produção sobre os anagramas, refletido na quase inexistência de rasuras em seus cadernos manuscritos.

Essa primeira carta sobre os anagramas, endereçada à Meillet, cumpre, portanto, um papel mais do que informativo. Trata-se de um documento que fornece ao leitor informações sobre o percurso teórico da hipótese anagramática. A interlocução aqui se faz necessária para o próprio andamento das pesquisas anagramáticas. Não é ao acaso que o interlocutor escolhido é um professor linguista, estudioso da gramática comparada. Para Saussure, se os dados analisados até o momento ainda não the forneciam uma certeza teórica, entendemos que um controlador externo, dotado de um saber erudito, poderia colaborar, refutando ou não, com o andamento da própria pesquisa.

As pesquisas sobre os anagramas se estendem até 1909, quando Saussure as interrompe abruptamente, após ter enviado as últimas cartas ao poeta Giovani Pascoli, que serão analisadas a seguir.

\section{A última carta de Saussure sobre os Anagramas}

As duas últimas cartas de Saussure sobre os anagramas foram endereçadas ao poeta italiano Giovani Pascoli, respectivamente em março e em abril de 1909. Esse poeta, além de professor da Universidade de Bolonha e tradutor da poesia clássica latina, foi também "[...] um dos precursores do movimento modernista na Itália." 14 (MAHONEY, 2006, p.347). É possível aventarmos a hipótese de que fora essa erudição no domínio da língua e da literatura latina que levou o genebrino a buscar uma interlocução com o poeta italiano.

Conforme pontuamos, as duas cartas endereçadas ao poeta Giovani Pascoli possuem alguns traços semelhantes àquela destinada a Antoine Meillet. O primeiro aspecto é a descoberta acidental dessas missivas. Durante a elaboração da Edição Crítica da obra Myricae, Giusepe Nava (1968) afirma tê-las descoberto ao acaso nos arquivos particulares

14 Tradução nossa de: "[...] one of the precursors of the Modernist movement in Italy.". 
do poeta, em Castelvecchio. Após essa descoberta, Giusepe Nava as publica nos Cahiers Ferdinand de Saussure, n. 24, de 1968, sendo também publicadas por Jean Starobinski, no livro As palavras sob as palavras, os anagramas de Ferdinand de Saussure, em 1971.

Na carta de 19 de março de 1909, Saussure (apud STAROBINSKI, 1971, p. 104) dirige as seguintes palavras ao poeta italiano:

Tendo me ocupado da poesia latina moderna a propósito da versificação latina em geral, encontrei-me mais uma vez diante do seguinte problema: - Certos pormenores técnicos que parecem observados na versificação de alguns modernos são puramente fortuitos ou são desejados e aplicados de maneira consciente?

Entre todos aqueles que se distinguiram em nossos dias, por obras de poesia latina e que poderiam, por conseguinte, me esclarecer, são poucos os que se poderia considerar ter dado modelos tão perfeitos como os seus e onde se sentisse tão nitidamente a continuação de uma tradição muito pura. É a razão que me leva a não hesitar em dirigir-me particularmente ao senhor e que deve servir-me de justificativa pela grande liberdade que tomo.

Caso o senhor estivesse disposto a receber em pormenor minhas perguntas, eu teria a honra de enviá-las numa próxima carta.

Conforme pontuam alguns estudiosos dos manuscritos anagramáticos, grande parte desses pormenores técnicos já figurava nas primeiras elaborações teóricas sobre os anagramas e são apresentados na primeira carta a Antoine Meillet ${ }^{15}$. Todavia, o destinatário nesta missiva tem um perfil singular: é poeta e, portanto, um possível conhecedor das leis anagramáticas, e é a partir desse aspecto que o genebrino justifica o envio da carta. No entanto, Saussure não possui a mesma intimidade pessoal com Pascoli como tinha com Meillet. Isso faz com que haja mais cautela em sua abordagem do tema, na medida em que anuncia os pontos que deseja saber: a possível casualidade dos anagramas ou, quem sabe, sua intencional utilização.

Se, na carta à Meillet, tem-se um pesquisador envolto com o fantasma da ilusão e da incerteza, aqui Saussure parece estar mais confiante em relação à sua última aposta: apoiar-se no saber do poeta, para certificar-se da veracidade do fato anagramático. De fato, ele expressa que o motivo da interlocução baseia-se nesse possível saber poético presentificado na pessoa de Giovani Pascoli.

15 Tais pormenores referem-se a princípios anagramáticos diversos, como a lei do manequim, do dífono, da presença de uma palavra-tema, etc., conforme Starobinski (1971), Testenoire (2013), Souza (2017), entre outros. 
Após essa primeira carta, Saussure escreve a segunda, em 19 de abril de 1909, tal como havia anunciado. Nesta segunda carta (e última sobre os anagramas), o mestre genebrino afirma

1. É por acaso, ou intencional que, numa passagem como Catullocalvos p. 16 o nome de Falerni se encontra rodeado de palavras que reproduzem as sílabas desse nome

... / facundi cálices hausere - alterni /

FA AL ER/AL-ERNI.

2. Ibidem p. 18, é ainda por acaso que as sílabas de Ulixes parecem procuradas numa sequência de palavras como

/Urbitum simul / Undique pepulit lux umbras.. resides

U---- $\quad$ UL U-------- ULI- X------ S--- S--ES

$[\ldots]$

Como eu dizia, esses exemplos, embora simplesmente escolhidos na massa, são suficientes. Há qualquer coisa de decepcionante no problema que propõem porque o número de exemplos não pode servir para verificar a intenção que pôde presidir o fato. Ao contrário, quanto mais o número dos exemplos se torna considerável, mais motivo existe para pensar que é o jogo natural de possibilidades sobre as 24 letras do alfabeto que deve produzir quase regularmente essas coincidências. Como o cálculo das probabilidades a esse respeito exigiria o talento de um matemático experiente, achei mais direto e mais seguro dirigir-me à pessoa mais indicada para me informar sobre o valor a dar a esses encontros de sons. (SAUSSURE apud STAROBINSKI, 1971, p. 105).

Nessa missiva, Saussure não se interroga sobre a possível ilusão do fato anagramático. Valendo-se de que os versos selecionados foram escritos pelo próprio destinatário, ele o questiona se tal composição poética fora elaborada com base nos fragmentos de nomes específicos: no primeiro verso, Falerni, e no segundo, Ulixes. Nesse sentido, a grande questão é saber se as possíveis formações anagramáticas são intencionais, utilizadas como recurso poético, ou se são encontros fônicos aleatórios.

Embora a produção saussuriana sobre os anagramas já esteja avançada no momento em que essa carta é escrita (após três anos de pesquisa e mais de uma centena de cadernos manuscritos), Saussure não se deixa levar pelo aspecto quantitativo desta teoria, baseado nos inúmeros exemplos obtidos. Ele está, portanto, consciente do fator probabilístico, isto é, de que as próprias letras do alfabeto podem contribuir para a presença de formações anagramáticas de forma acidental. 
Com base nas cartas até agora encontradas, essa interlocução com o poeta parece ser uma das últimas tentativas saussurianas de certificar se o fato era algo intencional, ou fortuito. Os autores são unânimes em considerar que o poeta Giovani Pascoli não respondeu à última carta sobre os anagramas. Starobinski (1971, p. 106), por exemplo, defende que "[...] o silêncio do poeta italiano foi interpretado como um sinal de desaprovação [...]", levando Saussure a não mais pesquisar as formações anagramáticas.

Mesmo que a problemática da intencionalidade não tenha sido solucionada, permanecendo um mistério para o genebrino, o fato é que a teoria sobre os anagramas figura como uma elaboração consistente sobre os fatos de língua e de linguagem, especificamente no domínio dos textos literários. Essa carta enviada, portanto, cumpre não somente um papel de interlocução, como também reflete a tensão entre um saber que se desconhece e a busca pela erudição, personificada na pessoa de Giovani Pascoli.

Essas interlocuções assumem um papel de relevância para a compreensão do movimento teórico de Saussure, não restritos somente às cartas enviadas. Nesse sentido, passemos agora a uma reflexão sobre as "cartas não enviadas" de Ferdinand de Saussure, tendo em vista, principalmente, a necessidade de compreender e de destacar a importância desses documentos, tanto para Saussure como para os pesquisadores saussurianos.

\section{Cartas não enviadas}

O registro de uma carta não enviada não é comum, sendo ainda mais incomum a publicação desse registro. Selecionamos dois documentos escritos por Saussure e que deveriam ser remetidos, mas não foram. Eles não pertencem ao gênero carta stricto sensu, mas poderíamos dizer que pertencem a um gênero híbrido. Contudo, não é o nosso foco discutir gênero, e sim propor uma reflexão sobre documentos importantes do linguista genebrino que tinham um destinatário e não chegaram ao seu destino por obra e vontade do seu autor.

O primeiro é o documento conhecido como Souvenirs, arquivado na Biblioteca pública de Genebra sob a rubrica 3957-1. Escrito pelo genebrino em 1903, com o objetivo de ser enviado para Wilhelm Streitberg (1864-1925), com quem ele já havia trocado correspondência, o tema do documento era a hipótese de plágio no seu único livro publicado em vida, conhecido como Mémoire. O Souvenirs foi planejado como um apêndice desse livro, o que não aconteceu. Saussure não o publicou nem o mostrou a ninguém, pensando, por fim, em transformar Streitberg em depositário do documento, mas também não o enviou. O documento foi, enfım, entregue à biblioteca de Genebra pelos seus familiares e publicado, 57 anos depois, por Robert Godel. 
O documento tem tom intimista e retoma o seu interesse teórico pela linguagem desde o ambiente familiar, na sua infância, como nesse fragmento em que ele relembra a leitura do livro de Pictet, na adolescência:

A ideia do livro e de toda a linguística da época, encontrar a vida dos povos desaparecidos, me inflamava. Um entusiasmo inigualável em sua ingenuidade; e não tenho lembranças mais requintadas ou reais de gozo linguístico do que aquelas que ainda hoje vêm a mim das baforadas dessa leitura de infância (folha 5) ${ }^{16}$.

Ou, então, quando ele afirma "Não há ninguém que, analisando esse livro, não possa muito legitimamente e naturalmente supor que ele é um dos frutos, bons ou não, do jardim de Leipzig."17.

Se, no primeiro fragmento, ele rememora a infância tal qual estivesse no divã de um analista, no segundo ele justifica o conteúdo do seu livro que está sob suspeita de plágio. Todas as duas situações, com temas acadêmicos, seriam constrangedoras em público e impensáveis no contexto acadêmico, ainda mais da conservadora Suíça do século XIX. Assim, de fato, compreende-se porque Saussure escolheu um fiel depositário, e não uma publicação, por exemplo. Mas, por que esse documento não foi enviado? O que isso nos ensina sobre a formação do linguista?

O outro documento que trazemos para a reflexão é escrito em 1894 e está arquivado na Biblioteca de Genebra sob o nome Notas para um artigo sobre Whitney, rubrica 3951-10. Na verdade, trata-se de um convite da Associação de Filologia Americana, para participar com um artigo na Reunião do Memorial de Whitney na Filadélfia, em 28 de dezembro de 1894. Saussure inicia esse texto, mas, em um determinado momento do manuscrito, intercala com a escrita de uma carta

Ao recebimento da sua muito apreciada carta, datada de Bryn Mayer, 29 de outubro, recebida em 10 de novembro, meu dever (teria sido), se eu a tivesse entendido claramente, responder-lhe imediatamente o seguinte.

16 Tradução nossa de: "l'idée même du livre et de toutela linguistique de cette époque - retrouver la vie des peuplesdisparus m'enflammait d'un enthousiasme sans pareil en sa naïveté; et je n'ai pas de souvenirs plus exquis ou plus vrais de jouissance linguistique que ceux qui me viennent encore aujourd'hui par bouffées de cette lecture d'enfance".

17 Tradução nossa de: "il n'est personne qui, en jugeant ce livre, ne doive très légitimement et très naturellement supposer qu'il est un des fruits, bons ou mauvais, directement sortis du terroir leipzigois". 
$1^{\circ}$ Você me dá grande honra de me pedir que considere Whitney como um filologista comparado. Ele nos deixou apenas dois trabalhos que inferem dos resultados da gramática comparada uma visão superior e geral sobre a linguagem: sendo essa, justamente, sua grande superioridade desde 1867, e sendo outra de suas originalidades o fato de indicar, sempre que tinha a oportunidade, que não confundia jamais a linguística com o estudo [...] Então é isso

$2^{\circ}$ Quando se trata apenas das coisas universais que se pode dizer sobre a linguagem, eu não me sinto de acordo com nenhuma escola, nem com a doutrina razoável de Whitney, nem com a doutrina desarrazoável que ele vitoriosamente combateu. E esse desacordo é tal que não comporta nenhuma transição nem nuance, sob pena de eu me ver obrigado a escrever coisas que não tem nenhum sentido a meus olhos

Eu deveria, portanto, Ihes implorar que me desobriguem imediatamente do dever de falar da obra de W em linguística, mesmo porque essa ocasião é de bastante [...], Todavia de nada serviria, visto o tempo[.... $]^{18}$

O artigo, que ficou inacabado, deixa claro o respeito de Saussure por Whitney, seu contemporâneo, e também a influência do americano em seu pensamento. Isso fica evidente quando ele cita a importância de Whitney ao asseverar que a linguagem é "uma coisa humana" em contraposição à ideia novecentista de que a língua pertencia a um reino da natureza.

Contudo, é patente a divergência do genebrino com o americano em relação a alguns pontos da sua teoria, notadamente naquilo que concerne à arbitrariedade do signo. Whitney acaba por sustentar uma noção de língua como representação do pensamento, que não era aceitável para Saussure, embora a sua teorização sobre a arbitrariedade ainda não estivesse constituída.

Além disso, sabemos que Whitney levantou a questão de que a língua é uma instituição social como as outras, louvável asserção no século XIX, mas ainda insuficiente para o genebrino. Para ele, a língua era uma instituição social muito específica sem paralelo com nenhuma outra.

Os dois documentos têm em comum, portanto, o fato de serem escritos para alguém, mas no decorrer da escrita algo impediu que seguissem o seu destino e eles amargaram em caixas de papéis durante décadas até serem lidos por alguém que não o seu autor. Texto inacabado de Saussure é comum, mas essa categoria não se confunde com o

18 Tradução publicada no livro Escritos de Linguística Geral, p. 183. 
texto não enviado, que é ainda mais incomum entre os escritos do genebrino. Os dois registros aqui elencados, dessa forma, compartilham essas duas características.

Já se constatou, também, por meio da análise de vários manuscritos saussurianos que a ocorrência de frases inacabadas é bastante comum, principalmente quando se constata a existência de um processo de elaboração conceitual. Ao que tudo indica, no Souvenirs, o genebrino expôs sua relação com a teorização da língua de maneira poética, por vezes retomando cenas familiares, descrevendo com detalhes certos funcionamentos da língua, fazendo relatos sinceros, muitas vezes, em relação a professores e colegas e, também, críticos no que se refere aos estudos da linguagem naquele período.

No texto sobre Whitney, ele principia por dar o devido estatuto às elaborações do linguista americano, mas, ao se deparar com posições do linguista que representam muito a linguística dos fins do século XIX, ele entremeia, no texto, alguns questionamentos e dá início às suas próprias elaborações, juntamente com o devido reconhecimento ao trabalho de Whitney.

O que não foi enviado pode ser comparado àquilo que está inacabado, tal como ocorre nos textos interrompidos, e também ao que está escrito, mas não se concorda mais e deve ser substituído por outro, como é o caso dos textos rasurados. O texto rasurado está proscrito, de certa forma como a missiva não enviada, mas, nesse caso, não parece que é porque ele discorda do conteúdo. O que parece marcar esses dois textos não enviados é de outra natureza. Ao que tudo indica é o excesso reconhecido nesses dois textos que os aproxima e impede que cheguem aos seus destinatários. Saussure se expõe em relação aos sentimentos, às opiniões, às concepções teóricas e abre espaços na escrita para ser lido sem ressalvas, o que, ao que parece, não convinha ao discreto linguista suíço.

\section{Considerações finais}

Abordamos, neste artigo, uma parte restrita do universo de cartas saussurianas que, conforme mencionamos, abrange mais de uma centena desses documentos. Tal amostra revela-nos pormenores interessantes sobre o percurso acadêmico saussuriano, talvez não explicitados em outras elaborações genebrinas concomitantes. Esses pormenores evidenciam, tanto nas cartas enviadas como nas retidas, o caráter perscrutador, perceptivo e analítico de Saussure, em suas incertezas, em seus descontentamentos com fatos passados, como também em se tratando de se posicionar sobre algum aspecto teórico de algum estudioso de sua época.

Nas cartas enviadas, cuja temática focalizava a produção sobre os anagramas, vimos como o genebrino constitui, talvez sem uma pretensão prévia, dois tipos de controladores externos. Na pessoa de Meillet, temos um controlador da hipótese anagramática 
associado tanto pelos laços de amizade, como também pelo saber linguístico que poderia agregar. Nessa relação, a carta objetiva o parecer do outro, de forma discreta, sobre a possível fantasmagoria do fato anagramático. Aqui, o genebrino se ancora no saber do amigo linguista, para que as pesquisas possam ser desenvolvidas.

O segundo e último controlador, Giovani Pascoli, é requisitado com base nos laços acadêmicos. As pesquisas, nessa altura, já estão saturadas pelo aspecto quantitativo. O objetivo de Saussure é, portanto, inquirir o saber poético, personificado no próprio poeta italiano. Ancora-se neste saber como a cartada final, visando descobrir o mistério que envolve os anagramas: os poemas de Giovani Pascoli também trazem formações anagramáticas. São conscientes ou não? Saussure logra êxito na primeira carta, que se trata de um convite, mas, na segunda, quando "abre o jogo", a resposta é dada por um silenciamento do poeta.

$\mathrm{Na}$ análise das cartas não enviadas, os temas são igualmente delicados, mas de outra ordem. Não dizem respeito a um estudo inédito de Saussure, mas sim ao seu estatuto de linguista eàs identificações e diferenças em relação aos seus contemporâneos, renomados estudiosos da linguagem. Entretanto, seus conteúdos causam constrangimento, porque ele não compartilha as mesmas posições éticas e teóricas em relação à linguística. Assim, o conteúdo poderia não ser bem aceito pelos seus interlocutores, causando um mal-estar no círculo de linguistas ao qual pertencia.

Contudo, a escrita do documento atesta a posição bastante clara de Saussure em relação aos estudiosos da linguagem de sua época, bem como a intenção de não confundir o seu trabalho com o deles. Posição que favoreceu um descolamento teórico e a fundação do que hoje conhecemos como Linguística Moderna.

Desse modo, é importante reconhecer que a análise das cartas saussurianas aqui apresentadas evidencia, para além de informações como datações, inícios e encerramentos de produções, aspectos singulares do percurso de Saussure enquanto linguista do século XIX. De fato, a natureza dessas cartas, e de outras a serem analisadas, pode contribuir para a compreensão do movimento teórico de um linguista em torno da linguagem humana, em suas diversas manifestações.

\section{REFERÊNCIAS}

BENVENISTE, É. Lettres de Ferdinand de Saussure à Antoine Meillet. Cahiers Ferdinand de Saussure, 21. Genève: Librairie E. Droz, 1964. p. 91-125.

FEHR, J. Saussure entre linguistique et sémiologie. Traduit de l'allemand par Pierre Caussat. Paris: Presses Universitaires de France, 2000. 
GODEL, R. Inventaire de Manuscrits de F. de Saussure remis à la Bibliothèque Publique et Universitaire de Genève. Cahiers Ferdinand de Saussure, 17. Genève: Librairie E. Droz , 1960. p. 5-11.

JAKOBSON, R. A primeira Carta de Ferdinand de Saussure a A. Meillet sobre os anagramas. Poética em Ação. Tradução Sandra Nitrini. São Paulo: Editora Perspectiva, 1990. p. 3-13.

MAHONEY, A. Poetic Play: Pascoli's Catulocalvos and Catulus 50. International Journal of the Classical Tradition, v. 12, n. 3, p. 346-363, Winter, 2006.

MARINETTI, A.; PROSDOCIMI, A. L. Saussure e il Saturnio-Trascienza, biografia storiografia. Cahiers Ferdinand de Saussure, 44. Genève: Librairie E. Droz, 1990. p. 37-71.

NORMAND, C. Saussure. Tradução Ana de Alencar e Marcelo Diniz. São Paulo: Estação Liberdade, 2009.

NAVA, G. Lettres de Ferdinand de Saussure à Giovanni Pascoli. Cahiers Ferdinand de Saussure, n. 24. Genève: Librairie E. Droz, 1968. p. 73-81.

QUIJANO, C. M. Le Cours d'une vie - portrait diachronique de Ferdinand de Saussure. Nantes: Éditions Cécile Defaut, 2008.

SAUSSURE, F. de. Escritos de Linguística Geral. Texto organizado e editado por Bouquet e Engler. Tradução Carlos Augusto L. Salum e Ana Lucia Franco. São Paulo: Cultrix, 2004.

SAUSSURE, F. de. Curso de Linguística Geral. Editado por Charles Bally \& Albert Sechehaye com a colaboração de Albert Riedlinger Tradução A.Chelini, J. P. Paes e I. Blikstein. 5. ed.S ão Paulo: Cultrix, 1973.

SAUSSURE, F. de. Souvenirs de F. de Saussure concernante sa jeunesse et ses études. Cahiers Ferdinand de Saussure - CFS. v. 17, Genève: Librairie E. Droz, 1960. p. 12-25.

SAUSSURE, F. de. Récit Autobiographique de sa jeunesse et de ses études: 3957-7. Bibliotèque de Genève, 1903.

SAUSSURE, F. de. Notes écrites en vue d'un article sur W. D. Whitney. 'Papiers Ferdinand de Saussure': 3951-10. Bibliotèque de Genève, 1891. 
SILVA, K.A. Breve estudo sobre os anagramas e sua relação com a teoria do valor em Saussure. Revista Letras \& Letras, Uberlândia: EdUFU, v. 25, n. 1, p. 145-160,jan./jun. 2009.

SILVEIRA, E. As marcas do movimento de Saussure na fundação da linguística. Campinas: Mercado de Letras, 2007.

SOUZA, M. Os anagramas de Saussure: entre a poesia e a teoria. Uberlândia: EdUFU, 2017.

STAROBINSKI, J. As palavras sob as palavras: os anagramas de Ferdinand de Saussure. Tradução Carlos Vogt. São Paulo: Editora Perspectiva, 1971.

TESTENOIRE, P.-Y. Ferdinand de Saussure: à la recherche des anagrammes. Limoges: Lambert-Lucas, 2013. 